\title{
A Proposal for the Development of Pre-Primary Education in Saudi Arabia Based on the Experiences of Malaysia and South Korea (A Comparative Study)
}

\author{
Ali Naser Al-Mogbel \\ Department of Educational Foundations, Taibah University, Almadinah, KSA \\ Email: drali252@gmail.com \\ Received 30 September 2014; revised 22 October 2014; accepted 15 November 2014 \\ Copyright (C) 2014 by author and Scientific Research Publishing Inc. \\ This work is licensed under the Creative Commons Attribution International License (CC BY). \\ http://creativecommons.org/licenses/by/4.0/

(c) (i) Open Access

\begin{abstract}
This study aims to identify the most important key features of pre-primary education in South Korea and Malaysia and the possibility of benefiting from their experiences in the development of this phase of education in Saudi Arabia, given certain circumstances and possibilities. This study identifies the similarities and differences through a review of the experiences of South Korea and Malaysia with respect to pre-primary education. The study subsequently analyzes and compares the results with the status of pre-primary education in Saudi Arabia to conceive a proposal for the development of a pre-primary education program in Saudi Arabia. The results of this study indicate that many factors have delayed the progress of pre-primary education in Saudi Arabia, including cultural factors and the unexpected and unplanned economic boom. The study suggests increasing the complementary relationship with the private sector through the granting of facilities to invest in the creation of excellent programs and pilot projects in kindergarten. In addition, the study suggests maintaining the quality of programs offered by enriching the integration of technology into the curriculum and directing pre-primary education curricula to focus on children's self-respect and on teaching through play, cooperative learning, and role-playing. The study further suggests that Saudi Arabia can benefit from the creative approach incorporated in Malaysia and South Korea based on the educational philosophy to meet the needs of children. The outcome of this study is a proposal for the development of a pre-primary stage education program.
\end{abstract}

\section{Keywords}

Curriculum, Development, Pre-Primary 


\section{Introduction}

The acceleration in scientific developments, the explosion of knowledge and the progress in technology are considered major characteristics of our time. As such, they influence the bodies concerned with education in both the developed and developing countries that are seeking to create and adopt modern technology through change and through the continual search of that which would lead to the country's greater efficiency and effectiveness. Thus, based on a deep belief that the education component is the most efficient in the promotion of communities and in keeping pace with advancements and developments, education is the key factor in meeting the needs of this era, and accordingly, the demands of this component must be fulfilled.

These changes and advancements in technology have influenced many countries around the world to review their educational systems and to take the necessary steps to reform, develop, and enhance them. Education and learning along with the development of human resources are considered the essential foundations of sustainable development (Mohammed, 2002: p. 39).

States and countries differ in their philosophies, objectives, plans and strategies related to education. On the one hand, some states and countries are concerned only with developing or enhancing their organizations, plans, human cadres and materials. On the other hand, there are those states and countries that are focused on improving education and its development to raise the efficiency of their organizations administratively, technically and procedurally. Accordingly, countries must develop polices in response to external and internal changes to improve performance, enhance the working environment and increase production efficiency so that their organizations are flexible, renewable and have the ability to absorb new knowledge to the point where they can occupy pioneer levels in many fields. The conscious perception to change is the key factor behind the success of educational institutions and educational excellence. By treating educational systems as social systems that are scalable for growth and development, the educational systems will be better able to meet the challenges and adapt to rapid changes.

If the development of education in developed countries is a major priority, then it is essential that the development of education in Arab countries be given higher priority and be awarded greater political and financial support than any other development. Furthermore, the emphasis on education development and its curriculum must not be limited to the state alone, but rather, it must be a shared responsibility that includes all stakeholders - the students, families, society, private sector and civil institutions-that are affected by the outcomes and outputs of the education system.

The countries of the world are aimed at upgrading the educational process and consider the level of attention given to the preparation of the learner's education a measure of the civilization of the nation. Many educators perceive the improvement of education as the best investment in comprehensive human development. This improvement begins with the investment of human capital that possesses capabilities, skills and competencies.

\section{Motivation for the Study}

The motivation behind this research as is detailed.

-The educational systems in various developed and developing countries struggle as the result of changes caused by continual advancements in science and technology. These changes influence modifications and give rise to new concerns for pre-primary education, thus necessitating the need to access various international experiences in this field.

-Economic, social, cultural and technical changes have resulted in changes in attitudes, expectations and human needs. Therefore, it is essential that mechanisms to change the administrative structures, operational methods, curriculum content and teaching methodologies and techniques in educational establishments be adopted so these educational institutions can function efficiently and effectively.

-There is an urgent need to study the educational aspects of Asian communities as most of the studies and research available in the extant literature focuses on economic and political aspects of education and ignores other aspects (Salim, 1995: p. 85).

-The last three decades have increased awareness and interest in the importance of pre-primary education and its implications academically, mentally, psychologically and socially with respect to the development of the child. This increased awareness has encouraged research in all countries of the world, including those countries compared in this study, to examine the role of this pre-primary stage in the formation of the child, specifically with respect to the forming of the child's identity and the degree to which it prepares the child for future stages 
of development. Table 1 presents some of these studies.

-Many Arabic educational research studies focus on studying Western educational models, in particular Britain, the United States, France and Germany, which may suggest that these models are perceived as distinguished and are therefore worthy of imitation and simulation. Systems and models of educational excellence from other countries, such as Malaysia and South Korea, however, have also experienced progress and success. Most of the educational comparison studies conducted in the Arab world that dealt with the pre-primary education stage (kindergarten) focused on educational, technical or administrative aspects and concentrated on comparing these aspects with Western models, particularly American and European models. The following is a list of some of these studies.

The study conducted by Abu Bakr and Ali (2013) focuses on a comparison of the requirements for the development of a kindergarten program in Egypt in light of the experiences of the United States and France.

The work by Mohammed (2006) provides a comparative study of training programs for kindergarten teachersin-service in Egypt and the United Kingdom in light of the global goals for kindergarten.

The global goals for kindergarten programs necessitate the need to change the direction of educational research and examine the relevant educational experiences of countries, particularly Asian countries such as South Korea and Malaysia, due to the social, cultural and educational progress. Furthermore, it is important, to identify the factors that contributed to the countries' social, economic, human and technological development and progress and to understand the role of education in this progress to benefit from their experiences. The intent of the study is to identify the elements of excellence given that both developed and developing countries today are in a downward spiral and are struggling with the economic, social and cultural changes caused by the tremendous advances in science, technology.

The study by Abdul-Halim (2002) investigates the development of a training system for kindergarten teachers in light of the experiences of certain developed western countries.

\section{Literature Review}

"Many educational approaches appear to be looking toward a better future and strive toward improving the educational processes as a whole; certain of these famous trends are quality future schools that incorporate moral and ethical trends in the educational process. Kindergarten in general and teacher preparation in particular are given special attention. Most countries require a university education for kindergarten teacher preparation. The International Union of Education in Early Childhood and the National Association for The Education of Young Children (NAEYC) recommend that kindergarten teachers must have university level preparation with a study period in a college program that is between four to six years" (Sasila, 2008).

Given that the trend towards the adoption of a culture of quality is one of the most important and prevalent tracks in modern education, the concept of quality evolved to address the following aspects such as overall quality, overall quality management, quality assurance, accreditation in higher education institutions and other terms and concepts that emerged from the adoption of quality in education. Quality is defined as a description or a degree of the exceptional excellence of a product (Al-Mahyawi, 2007: p. 140), and thus, quality in education

Table 1. Studies on pre-primary education.

\begin{tabular}{ccc}
\hline Country & Reference of Study & Year \\
France & McMahan (1992) & 1992 \\
USA & Schweinhart et al. (1993) & 1993 \\
Germany & Tietze (1987) & 1987 \\
Britain & Osborn \& Milbank (1987) & 1987 \\
Sweden & Ochiltree \& Edgar (1990) & 1990 \\
Singapore & Sim \& Kam (1992) & 1990 \\
South Korea & Rhee \& Lee (1990) & 1983 \\
Australia & Braithwaite (1983) \\
Ireland & Le Normand (1992) \\
\hline
\end{tabular}


means to judge the level of achievement with respect to the goals and values of this achievement, the activities associated with this provision and the outputs that include the features and characteristics regarding certain approved standards (Hussein, 2005: p. 150).

Fraiwan defines a quality higher educational institution as one that has the ability to plan policies and accomplish tasks that would develop creative and innovative learners, thus allowing the Arab nation to keep pace with current advancements and changes (Fraiwan, 2007: p. 243). The adoption of the concepts of quality education can only be achieved through informed interactions about educational experiences in other states and communities. The extrapolated excellence and features of success achieved in some countries, including Asian countries, especially countries that have achieved distinguished educational successes such as South Korea and Malaysia, call for scientific research in the field of educational studies to determine the comparative success points in these countries’ experiences.

A number of developments evolved during the twentieth century have had an impact on the family and the role the family plays in the upbringing of their children prior to pre-primary education. The expansion of the opening of nurseries and kindergartens to care for children during this early stage of life on behalf of their families or in cooperation with their families has supported the existence of the role of pre-schools and kindergartens as evidenced by scientific studies of children enrolled in primary education the age of six regarding the benefits accrued by children enrolled in these institutions compared to children not enrolled in these institutions (Al-Shayji, 2013).

The present study aims to clarify the pre-primary (kindergarten) education offered in Malaysia and South Korea, to identify certain rules and principles that can guide the evaluation of this stage in Saudi Arabia and to facilitate in the development of a proposal regarding the establishment of pre-primary education in Saudi Arabia.

"Education is no longer isolated from what is happening in today's world of transformations and changes, but it is undoubtedly influenced by these changes and it also has an effect on these changes according to its flexibility and openness. There are global trends that impose their influence on many areas and activities of life. Education is one of those areas. It is the most sensitive and the area most affected by changes happening around it. Thus, innovations in the education system are a necessity and not an education luxury or an option than can be ignored under any circumstance (Al-Aqeel, 1426: p. 220). The human being is the developmental tool and the real investment behind the achievement of economic and social growth; therefore, it is important that educational systems raise their level of performance and continue the quest for education reform and development” (Hamed, 1426: p. 305).

Recent attention has been directed towards educational reforms in various aspects of the educational system in the Arab world. Thus, it is consistent with the current advancements and accelerating developments of the time. Hence, some countries have initiated the development of the educational process, as well as educational ladders for the different stages of education, including pre-primary education (kindergarten) with respect to curriculum content, teaching methodologies and techniques, learning activities and associated materials.

John Dewey called for the development of programs, activities and methodologies that can be adapted to the child's interests and abilities and, in turn, will enhance the child's social skills and human relations (Badran, 2000: p. 121).

The last two decades have seen a growing interest in this pre-primary stage with the active movement towards establishing kindergartens in the Arab world, particularly in the area of curriculum design, which targets the development of the child in the first two years of schooling.

English author and thinker George Bernard Shaw says, "What we want to see is the child in pursuit of knowledge, not knowledge in pursuit of the child". In addition, Shaw emphasizes the importance of childhood and the enhancement of knowledge in the child. The early stage of childhood education is integral for the growth and development of children, especially with respect to the development of the brain, which is directly influenced by the quantity and quality of stimuli and early experiences to which to the child is exposed, especially in the early years.

Multiple studies have shown that children in their first five years of life who have been introduced to experiences and stimuli designed for academic intent exhibit increased motivation, a desire to learn; and an appreciation for themselves that exceeds that of children who were not exposed in early childhood to such planned programs and experiences. Others believe that experiences children have in early childhood are critical and important for the development of the brain and the interdependence of cell-based networking, which help in the learning and thinking processes. Moreover, these early childhood programs whether in the family or in pre-school 
children institutions, definitely help prepare children for success in subsequent stages of education (Meisels, 1999).

There are efforts being made to develop and upgrade this important educational stage in Saudi Arabia, including the adoption of new curriculum developed for kindergarten children. This new curriculum includes important values as well as basic life and learning skills. It also includes the implementation of a national strategic plan for early childhood education. These efforts are the results of the challenges that dictated changes and developments in this era and of the developments in the cognitive, cultural, demographic aspects of specialized studies and research in the areas of childhood and education.

Hence, the importance of comparative studies, according to the requirements of the current technology and in light of the rapid scientific developments, is that they allow access to international experiences in education, and thus, this study examines the elements of excellence to develop educational practices and improve mechanisms for working in the field of educational.

\section{Methodology}

The present study examines the pre-primary education programs in South Korea and Malaysia with the intent to improve and develop mechanisms for this educational stage in Saudi Arabia. The goal is to propose a suitable plan for improving pre-primary education in Saudi Arabia.

The problem statement of this study is defined through the following questions:

How can Saudi Arabia develop a pre-primary education program based on an examination of the experiences of Malaysia and South Korea?

This overarching question gives rise to the following sub-questions:

-What are the attributes and features of pre-primary education in South Korea?

-What are the attributes and features of pre-primary education in Malaysia?

-What are the similarities and differences between the pre-primary education programs in South Korea and Malaysia?

-What factors from the South Korean and Malaysian programs should be incorporated in the proposal for the development of pre-primary education in Saudi Arabia?

This comparative study analyzes and interprets the various aspects and formulas for pre-primary education in both South Korea and Malaysia. Given the cultures of these two countries, a proposal can be conceived for the development of this stage of education in Saudi Arabia. Hence, this study makes the following contributions.

1) This study will add to the extant comparisons of educational research and thus benefit professionals and researchers in the field.

2) This study will provide a definitive answer to the research problem.

3) This study may cause certain aspects of pre-primary education to be reconsidered and perhaps revised.

This study aims to identify the most important key features of pre-primary education in South Korea and Malaysia and to possibly benefit from the experiences of these countries as Saudi Arabia seeks to develop this early phase of education and to develop a proposal taking into consideration various circumstances and possibilities.

There are several limits associated with this study.

-Geographical boundaries (spatial): the study was limited to an examination of pre-primary education only in South Korea and Malaysia.

-Objective limits: The comparison study of pre-primary education was limited to the following themes:

1) Community political, economic and social features.

2) The educational and organizational structures of different stages of public education.

3) Pre-primary education.

-Time limits: 2012/2013 academic year.

There is consensus among specialists in education that the pre-primary phase of education be called "kindergarten", which is the educational stage that precedes the primary stage. However, there are also multiple denominations within this pre-primary stage such as kindergarten, nursery, early childhood education and pre-school education. Accordingly, all of these terms suggest that kindergarten, which receives children who are at least three years of age, promotes the welfare of children, takes care of their physical, mental and psychological growth, and facilitates their transition from home life to school education (Al-Fayez, 1418: p. 3). 
A dictionary of education terms further defines kindergarten as "an educational institution dedicated to the education of young children between the ages of 3 and 6 years and is characterized by several activities designed to give children an education, social values, opportunities for self-expression and training on how to work and live together" (Al-Rashed, 1419: p. 9).

The author of this study procedurally defines the term pre-primary education as the educational stage attended by children from the age of 4 to 6 years that precedes the first stage of basic education (primary). It is also known as kindergarten.

This comparative study considers the most suitable and meaningful approaches incorporated in the curriculum and used in comparative education. The comparative approach is a comparative study that identifies the similarities and differences in the curricula that extend beyond the acquisition of precise knowledge. Herein, the experiences of South Korea and Malaysia with respect to their pre-primary education programs will be reviewed and analyzed, and the results will then be compared with the reality of implementing a pre-primary education program in Saudi Arabia. A proposal for the development of pre-primary education in Saudi Arabia will then be visualized. The comparative approach is considered the axis of the scientific method from which inferred similarities and differences can be observed as can the correlative variations in the incidences and causes with reasonable grounds for comparisons that result in a better understanding of the phenomenon being studied (Al-Rashidi, 2000: p. 79).

\section{An Analytical Study of Pre-Primary Education in South Korea and Malaysia}

\subsection{South Korea}

South Korea occupies the southern half of the Korean peninsula in Southeast Asia and covers an area that is 965 $\mathrm{km}$ in length and $217 \mathrm{~km}$ in width. Of this area, 75\% is mountains (Fathi et al., 1996: p. 211). Its coastline is rocky and steep, and it has a continental climate. Due to its climate and difficult terrain, South Korea encountered enormous challenges in the twentieth century. Because it was controlled by Japan for more than thirty-five years, there has been a strong link in education between the two countries imposed by Japan's control of the relationship. While the roots of education in Korea can be traced back to the establishment of the first regular school in $372 \mathrm{AD}$, the current modern educational and organizational structure has existed for less than fifty years. Thus, the administrative system in South Korea is based on many foundations and principles derived from its long history and heritage of this early education that was inherited through the reforms carried out by King Tiggo, the first king of the new ruling family (Fathi et al., 1996: p. 216).

\subsubsection{Education in South Korea}

The education system in South Korea is a modern system that focuses on enhancing learners' skills and basic capabilities and is dedicated to the qualitative development of scientific education. It emphasizes modern culture and shares a significant role in the development of creative, conscientious, hard-working, ethical individuals. The educational system itself is committed to improving the prominence of education as it is concerned with raising children, building their bodies; developing their language skills, intelligence and social adjustment; instilling values in them; and influencing their behaviors (Al-Hamundy, 2010).

Not surprisingly, South Korea is ranked as the tenth richest country in the world, and it ranks third among the largest economies in Asia after Japan and China. This is in sharp contrast to its being ranked the third poorest country in Asia in the mid-1900s. South Korea, a nation with few natural resources and a high population, considers education to be the key to success, both in the present and in the future. Accordingly, it considers the investing in human resources as its most important investment and has achieved tremendous success due to this strategic vision. The Korean society realizes that the best way to advance vocationally and practically is through education.

The Korean education system was built by borrowing from other modern educational systems and by creating harmony between these modern concepts and the ever-present Confucian teachings and philosophy of education that is deeply rooted in the culture of educators. As the Confucian philosophy considers education to be the only key to success in the present and the future, exceptional attention has been given to education.

The author believes that the upholding of learning as a value, the interest in the development of modern education, and the philosophical underpinnings are the tools that led to the superiority of South Korea's education system and that have allowed South Korea to keep pace with global developments in the various fields. 


\subsubsection{The Structure of the Education System in South Korea}

1) Kindergarten enrolls children between the ages of four and six. As these institutions are not public, they are not mandatory. The aim of these institutions is to elevate children by building their bodies, developing their language abilities, their intelligence and their emotional growth, and instilling the values necessary for their social adjustment and behavioral growth.

2) Universal primary education is a compulsory six-year educational program. It is free to all children between the ages of six and twelve and is provided by the State. Primary education is the beginning of free compulsory education and $99.8 \%$ of the children who have reached the age of six years are enrolled in this system (Khalil, 2002: pp. 135-136).

3) Middle school education is compulsory. It is a three-year program for children between the ages of twelve and fifteen years. Thus, children in South Korea are required to attend school for nine years, that is, between the ages of six and fifteen years (Khalil, 2002: pp. 136-137).

4) Secondary education consists of three years and is attended by students between the ages of fifteen to eighteen years. While it is not mandatory, it is free. Even though high school/secondary education is not mandatory, the proportion of students who complete middle school and enroll in high school is $94 \%$. This indicates the status that education holds among the people of South Korea who consider secondary education a specialized stage.

Senior secondary schools in South Korea are divided into two types: academic and vocational. However, there are also comprehensive schools, marine schools and crafts schools (Khalil, 2002: pp. 137-138; Korean Overseas Information's Service, 2004).

\subsubsection{Pre-Primary Education in South Korea}

South Korea has faced significant challenges in the twentieth century while its people were under the control of Japan for more than 35 years. As a result of Japan's control, many of South Korea's experiences are similar to those of Japan. For example, Japan's basic education system targets "gaining skills, promoting basic capabilities, developing qualitative practical education, expanding modern culture, participating in the development processes through the building of conscientious creative humans committed to productivity and characterized by noble morality". Furthermore, the beginning of achieving these goals does not start at the primary level, but rather at kindergarten as it is here where children are introduced to the basic building blocks necessary to build the personal characteristics that will lead the child to future success. Table 2 provides a summary of kindergarten education in South Korea.

\subsection{Malaysia}

Malaysia, which is located in Southeast Asia, is a federal kingdom consisting of the Malaysian peninsula that includes 11 federal states known as West Malaysia and East Malaysia. The total area of Malaysia is 329,758 $\mathrm{km}^{2}$. Both the eastern and western portions are located in Southeast Asia near the equator, and as such, it includes a large area of land on the sea route from India to China, which mediates the distance between them. As most of its territory is surrounded by water, the length of the coast of Malaysia is 3000 miles from the Indian Ocean to the South China Sea. The length of the coast of Sarawak and Sabah, i.e., East Malaysia, is approximately 1400 miles. With respect to demographics, Malaysia's population is 27,757,000 according to the 2008 census. This represents $0.41 \%$ of the total world population. Malaysia was aware of the importance of addressing the problem of population out of fear of its continuing increase. Therefore, through different educational programs and curricula, Malaysia attempted to address this crisis by incorporating concepts of population education programs in the training and preparation of teachers (Al-Zaki, 2010).

The population consists of several races that migrated to this part of Southeast Asia during ancient historical

Table 2. Kindergarten in South Korea.

\begin{tabular}{cl}
\hline Legal age & 4 to 6 years \\
& -Emotional language development \\
Main interest & -Physical growth \\
& -Growth of general intelligence and social adjustment \\
Role & -Educational achievement \\
\hline
\end{tabular}


times. The Malawians, who belong to the Mughal genus, make up 46\% of the total population and are considered the most important race. This is followed by the Chinese in second place, as they comprise approximately $37 \%$ of the population of Malaysia. The Indians and Pakistanis account for approximately $9 \%$ of the population, while the remaining $8 \%$ of the population is made up of Arabs, Japanese, and various European ethnic groups. Because the different races have different religions, the Malaysian constitution guarantees the freedom to worship for all (Abdul-Aal, 2006).

The official national language of Malaysia is Malay, the language of education since 1967. The Malayan language is written using the Latin or Arabic alphabet, and it contains many Arabic words. However, there are other languages and dialects used by people in various regions of Malaysia because of the different ethnic groups. The Chinese, for example, speak various Chinese dialects; the Indians speak Tamil and Hindustani among others, and the English language, which is a compulsory subject in Malaysian schools, is widely used in government departments, industries and trade. Accordingly, the Malaysian language is the language of learning at all stages of public education while English is learned as a second language. With respect to its economy, Malaysia's, one of the strongest in Southeast Asia, depends largely on the production of oil, rubber, timber, tin and several different agricultural crops (Global Arabic Encyclopedia 1416, Part 22: p. 139).

Since its independence in 1957, the economy began a structural transformation from a heavy reliance on tin mining and rubber plantations to an economy dependent on industry, quality work performance, and worker productivity. This transformation significantly influenced the development and quality of the educational sector as well as the depth of knowledge being taught. "Malaysia identified the year 2020 as the deadline to become a developed country, and it has already begun to actualize huge annual rates of progress by encouraging certain industries to become the mainstays of Malaysia’s economy” (Bashir, 2003).

Three decades ago, Malaysia started on its journey toward economic development. The financial crisis of August 1997, however, reduced its currency to half its value. Malaysia quickly recovered from this recession and became the strongest economy in Southeast Asia. This distinct Malaysian experience was a breakthrough in the development and advancement of the country. The economic situation is directly reflected in the country's education system through the provision of educational funds to provide free basic education. Accordingly, there are several economic factors that have contributed to the development of education in Malaysia.

1) The provision of skilled labor to keep pace with the country's economy, i.e., an economy that shifted from the traditional agricultural sector to the industrial sector. This transition called for a strong and active educational system.

2) The need for a highly skilled productive labor force compelled Malaysia to endorse college education to serve the economy and create programs for the development of modern higher education as well as public education in all branches and at all levels (Bashir, 2003).

3) The need for the government of Malaysia to create an ambitious plan for the country to be part of the information society by 2020. This goal forced the government to focus on developing and improving education by keeping up with technological advancements and requirements (Al-Warthan, 2011).

\subsubsection{Education in Malaysia}

The current Malaysian education system was influenced by many factors, including geographic, demographic, linguistic, social, religious, economic, among others, that have contributed to the formation of the Malaysian education system in its current form. Since its independence in 1957 from British occupation, education has become an integral part of its development policy. Therefore, the education sector went through ongoing and lasting changes and development processes during those years, while over the last thirty years, the state's efforts have mainly focused on uniting all segments of society through a uniform educational system that includes a national curriculum and an emphasis on a the use of national language for teaching and communication. This thirtyyear period also saw a significant increase in enrollment in the various stages of education (Bashir, 2003).

The State of Malaysia developed a strong educational system that met the needs of the skilled and active labor force, thus contributing to the economic transformation from the traditional agricultural economy to an industrial economy. Malaysia could not have achieved this sustained economic growth without investing in the human element, which is the most valuable asset owned by nations. An economy cannot grow unless it intensely invests in the human element, which has become the most important element in the production process of the information technology era as the development of a strong economy and civilization is contingent upon technological 
progress (Al-Warthan, 2011).

To create a quality educational program, the Malaysian government reformed the curriculum and increased the use of educational technology. The result was an effective and efficient administrative education system that ensured greater focus on the educational process within the classroom and on various administrative aspects in the educational system with an emphasis on the teacher. It is expected that further reforms and developments in the education and training systems in Malaysia are planned to achieve its many objectives. The most important objective is to ensure the creation of quality in education and training for all Malaysian citizens and to provide them with the knowledge and skills necessary for Malaysia to become a developed nation by 2020 (Al-Zaki, 2010).

The author believes that the education system in Malaysia is the story of successes and struggles experienced by the Malaysian society in the last few decades and that it is the result of strong-will, ambition, careful planning and quick effective action. Malaysia was once a country confronted with multi-ethnic troubles, colonial greed and conflicting interests from many directions. However, due to the development of its unique educational system, Malaysia achieved national unity and sustainable economic growth, which is clearly reflected by its investment in the human element, the most precious wealth possessed by a nations. Thus, Malaysia’s success in establishing a strong education system has helped to meet the need for a skilled labor force, which contributed to the effective economic transformation from a traditional agricultural economy to a modern industrial economy. Today, Malaysia is employing education as a tool to achieve a decisive phase in the knowledge economy that is based on information and communication technology.

The Malaysian government pursued several important educational policies (Bashir, 2003).

1) The government's commitment to free primary education.

2) The pursuit of pre-primary education (kindergarten).

3) A focus on primary education and a basic knowledge of national identity.

4) A direct secondary education focused on the service of national goals.

5) The establishment of teacher training institutes and industrial training programs.

6) A focus on achieving compatibility between technical developments and informatics.

7) A focus on the relationship between college education and the economy.

8) The establishment of a link between education and research activities.

9) The opening up of advanced educational systems.

10) A focus on educating females.

As stated in the Guide to Malaysian Studies (2003: p. 23), Malaysia’s strategic plan for 2020 call for making education a creative productive sector of the current economy, which will propel Malaysia into the information age. The official start of the school year in Malaysia is the first of January and it runs until the third week of November, thus allowing for a minimum of 190 school days in a single school year. As the Department of Education in Malaysia is national and centralized, it falls under the purview of the federal government (Malaysian Consulate, 2003).

Education, according to the philosophy of the Department of Education in Malaysia aims to prepare citizens in a dynamic, productive and humane way to face the challenges of the times. It also aims to prepare individuals mentally, spiritually, emotionally and physically based on a faith in God and obedience to Him. The educational curriculum provides students with the knowledge and skills necessary to contribute to the nation's development as the nation strives to advance its industrial sector and promote unity and prosperity of the family, community and nation (Ministry of Education, 2004).

Initially, education in Malaysia was free but not compulsory, though most schools in the country were government schools or received government support. Accordingly, Bashir (2003) argued that state mandated education is a logical consequence of the support and facilities that are provided by the government. Hence, today, education in Malaysia has become one of the things that is indisputable, and parents who do not send their children to school are subject to punishment under Malaysian law.

\subsubsection{The Organizational Structure of the Education System in Malaysia}

Education begins at the pre-primary level and continues through the general education program, which consists of two phases-primary and secondary. The educational system in Malaysia is organized according to a 6, 3, 2 scheme, that is, six years of primary education followed by three years of lower secondary education. At the end of this level, students take an exam and those who pass enter a two-year upper secondary school (Malaysian 
Consulate, 2003).

-Pre-primary education (kindergarten)

According to the Education Act of 1996, kindergarten in Malaysia is part of the national education system, and it is attended by children between the ages of four to six years (Ministry of Education, 2004).

-Primary education

Primary education is free but not compulsory; however, approximately $99 \%$ of the target age group attends the primary stage. These are children between the ages of six and twelve. This is a six-year stage that is divided into two, three-year periods. The first period goes from grade one to grade three and the second is from grade four to grade six. The focus of education during this six-year stage is to teach students to read, write and become familiar with basic knowledge in arithmetic and science. It also directs students towards science and technology through the two courses-human and the environment and active skills-that are offered beginning in grade four (Ministry of Education, 2004).

-Secondary education

The secondary education program in Malaysia consists of two phases:

1) Lower secondary school

Lower secondary school or middle school extends for a period of three years, with an additional year added for Chinese and Tamil students to help them master the Malay language, as it is the language of instruction at the secondary level (Al-Zaki, 2010).

2) Upper secondary education

Upon completion of middle school, students prepare for their final exam. A passing score on this exam qualifies them to attend a two-year upper secondary school. This level of education is provided by a group of academic, technical, professional, and religious schools, and students are placed into one of three tracks based on their performance on the lower secondary final exams (Fathi et al., 1996).

\subsubsection{Pre-Primary Education in Malaysia}

The implementation of pre-primary education is the responsibility of three ministries-education, rural development, and social affairs-in addition to certain private institutions. However, in spite of the diversity of bodies responsible for these institutions, all of the pre-primary institutions follow the curricula designed by the Ministry of Education whose aim it is to elevate the child in all aspects of life. Pre-school education is spread throughout the country with more than six thousand centers (kindergartens), all of which are required to be registered with the Malaysian Ministry of Education.

The Education Act of 1996 considered pre-school to be part of the federal education system, and as such, the government has focused on pre-school education, requiring all kindergartens to be registered with the Ministry of Education and to apply the curricula as prescribed by the Ministry of Education. The curricula, which outlines the general objectives of kindergartens, include teaching using the official language of the country while also permitting the use of English and other ethnic languages such as Chinese and Indian, teaching methodology, teaching methods of educational supervision and providing social and religious guidance. Pre-school education in Malaysia is free and is provided by many government agencies, private organizations and charitable organizations. In 1996, the percentage of children enrolled in kindergarten was $70 \%$ of all students enrolled in the first year of primary school (Fathi et al., 1996).

Children are enrolled in kindergarten between the ages of four and six years. Thus, pre-school education has become part of the national education system whereby all kindergartens in Malaysia are committed to teach the curricula offered by the Ministry of Education.

This approach is commensurate with the age group of these children and is consistent with the stage of their development, interests and needs. The curriculum is dynamic. It focuses on children, and it is sensitive to and compatible with the different races that may exist in one class. The objectives of the pre-school curricula emphasizes the understanding of attributes and characteristics of children by linking them to their local environment and strengthens the link between school and home.

The objectives of a pre-school education in Malaysia are many. For example, the child who attends kindergarten in Malaysia will

-develop a love for country,

-follow the religious teachings in life,

-practice noble values, 
-respect the national language,

-acquire English as a second language,

-develop self-esteem and a sense of appreciation and,

-encourage curiosity, creativity and an appreciation for beauty.

To achieve these objectives, kindergartens offer a variety of courses, namely, citizenship, Islamic studies, moral education, use of the national language, English education, language development, physical development, social development, emotional development, cognitive development, and creative and aesthetic development (Ministry of Education, 2004).

In general, the maximum teaching hours in kindergarten are three and a half hours per day, five days per week. While there are many schools that are managed by government agencies, organizations or the private sector, the best known agency providing pre-school education services is the union government pre-school agency, which has been offering its services since 1960. According to the Malaysian Ministry of Education statistics (Bashir, 2003), the Malaysian union government agency has been building kindergartens throughout the cities and urban areas since1976. Table 3 provides statistics on Malaysian kindergartens.

\section{Comparison between Pre-Primary Education in South Korea and Malaysia}

Table 4 shows the differences between Malaysia and South Korea in pre-primary education Malaysia and South Korea's approach to education is that the future begins with effective learning. Therefore, both countries direct their interest to the human, physical and technical capabilities as they build their educational systems. The education in both countries emphasizes building the human capacity from early childhood by enrolling them in pre-primary/kindergarten institutions. The study further shows a strong indication of increased interest in this educational stage as the number of kindergartens in these two countries continues to grow rapidly. This rapid growth in pre-school education has been followed by changes in the administrative and technical sectors of the education system. The vision of these supervising and organizing sectors with respect to education, in both countries, takes into account the unique aspects of the kindergarten stage. Accordingly, the administrative sectors recognize the need to focus on improving the components of the educational system-curricula, students, teachers, buildings, resources-at this important stage.

Table 3. Malaysian kindergarten statistics (2003).

\begin{tabular}{ccc}
\hline Item & Count & 1076 \\
\hline Public kindergartens & 27,883 \\
Number of children & 1189 \\
Number of classes & 1699 \\
Number of teachers & 2161 \\
Private kindergartens &
\end{tabular}

Table 4. Comparison of pre-primary education in South Korea and Malaysia.

\begin{tabular}{|c|c|c|}
\hline $\begin{array}{l}\text { The most prominent points of } \\
\text { comparison }\end{array}$ & South Korea & Malaysia \\
\hline State sovereignty & Controlled by Japan & Occupied by Britain \\
\hline Legal age & Age 4 - 6 years & Age 4 - 6 years \\
\hline Language spoken & Korean & Malaysian \\
\hline Supervisory responsibility & Non-governmental agencies & $\begin{array}{l}\text { Government, private and charitable } \\
\text { organizations }\end{array}$ \\
\hline Law & Currently not compulsory & Not compulsory \\
\hline Education & Free 20\% (private schools) & Free for all \\
\hline Objectives & Enhance skills, promote basic capabilities & Elevate the child in all aspects \\
\hline Aspects of the curriculum & $\begin{array}{l}\text { Physical growth; linguistics; emotional growth; } \\
\text { general intelligence; social adjustment }\end{array}$ & $\begin{array}{l}\text { Address all aspects of the child's emotional, } \\
\text { physical and social development }\end{array}$ \\
\hline
\end{tabular}




\subsection{Basic Features of the Community}

Many researchers conclude that the culture, traditions and moral values play an important role in the success of the economic development in Asian countries. For instance, the launch of the name "Asian Dragon" on the economies of the region suggests the role of cultural factors.

The teachings of the moral values of Confucianism that prevail in Southeast Asia has served as the foundation for all experiences of growth in those countries as it has created a culture committed to the values of hard work, respect for authority, honesty, and loyalty to the homeland. In addition, these teachings have contributed to the social and political stability in light of noticeable ethnographic, religious and cultural differences, and they have always promoted cooperation and collective participation while denouncing rivalry, divisiveness and mediocrity (Bashir, 2003). The most prominent moral values and traditions that are similar to both South Korea and Malaysia and that played an active and supportive role in the success of the development of the countries in general and in education in particular are as follows:

-Constructive modeling: Japan is the best example and preeminent role model for all developing and growing East Asian countries. Both Malaysia and Korea drafted the content of their strategies by mimicking, to some degree, those of Japan. The Japanese occupation of both countries has had a role in the spread of qualitative values and Japanese culture, including the positive aspects, especially those relating to perfection and persistence when striving to improve at a professional level (Abdul-Aal, 2006).

-Rules, literature and culture: These include simplicity and moderation in consumption. These values contributed to promoting other values such as the need to protect the national wealth, the proper use and employment of resources, and a respect and appreciation towards the elderly. This last moral value is reflected in the respect that people show towards authorities at all levels. Thus, the law governs public life and compels people to obey the state policies without impeding or opposing them (Abdul-Aal, 2006).

-Tolerance and ethnic homogeneity: Harmony among the different races in the countries studied in this work is dominant. This is particularly true with respect to the Malaysian people. Malaysia has three ethnic groups: Malayans comprise approximately 50\% of the population. While the Muslims and Chinese believe in Buddhism, the majority of Indians are Hindu. Regardless of the ethnic and religious differences, however, the country is marked by social and religious tolerance and a respect for the country's constitution (Al-Zaki, 2010).

\subsection{Organizational Structure of Education}

The two countries have a similar educational ladder. The public education systems, as explained herein, consist of the following stages.

South Korea: Kindergartens are non-mandatory, non-government institutions that enroll children between the ages of four and six years. Primary education requires six years of study and enrolls children between the ages of six and twelve years. It is free and compulsory. Middle school education consists of three years and enrolls children between the ages of twelve to fifteen years. While it is not mandatory throughout the country, it is required in some in some coastal (fishing) areas and agricultural areas. Secondary school consists of three years and is attended by students between the ages of fifteen and eighteen years. It, too, is free and non-mandatory.

The organizational structure of education in Malaysia consists of pre-school education (kindergarten), which is attended by children between the ages of four and six years. It is coordinated by three ministries-the Ministry of Education, Ministry of Rural Development, and the Ministry of Social Affairs-in addition to some private institutions. Primary education, which is free and not mandatory, is a six year program of study that is attended by children between the ages of six and twelve years. Secondary education, which is an extension of primary education, is divided into two stages-lower secondary education and upper secondary education-each of which is three years in duration.

The Malaysian and South Korean educational systems are similar in the initial phase of study, that is, the primary stage, but they differ in the secondary phase in that Malaysia's program is two years while South Korea's is three years.

\subsection{Pre-Primary Education}

Malaysia and South Korea's philosophy toward education is that the future begins with effective learning. Therefore, both countries focus their interests on the human, physical and technical capabilities as they develop 
their education systems. The education in both countries emphasized the development of the individual from early childhood through pre-school and kindergarten institutions. The study shows a strong indication of increased interest towards this educational stage as the number of kindergartens continues to grow rapidly in both countries. This rapid growth in pre-school education was followed by changes in the administrative and technical sectors of the education system. The vision of these supervising and organizing sectors with respect to education, in both countries, takes into account the unique needs at the kindergarten stage. Accordingly, the efforts during this important stage must focus on specific components of the educational system-curricula, students, teachers, buildings, resources.

The administrative and supervisory institutions in both Malaysia and South Korea show a movement toward developing educational policies that focus on the economic, educational and social investments at the pre-primary stage as this is the foundation for the formation of the personality of the human being of tomorrow. The current educational plans consider it an essential stage in the hierarchy of basic education as evidenced by the buildings and the autonomous budget for pre-primary institutions as it is these institutions that will provide the appropriate learning environment for the growth and development of the children. Thus, the focus of the educational goals for pre-primary education in these countries is on the mental growth and development of the child. While it is noted that there is an emphasis on the cognitive growth at this stage, the focus is not only on these objectives but also on the procedural goals, which must keep pace with the technological developments and scientific discoveries appropriate for this stage. Accordingly, the educational components and methodologies implemented in this phase must be specifically designed for the pre-primary child.

The pre-primary education (kindergarten) programs in both South Korea and Malaysia have adopted new goals intended to enhance the quality of education and care afforded the children in the pre-primary stage of education.

Based on the comparison conducted in this study, kindergarten plays an important in the psychological, educational and social development of children. For this reason, the governments of the two countries studied herein allocate huge budgets to ensure the enrollment of children in quality, integrated kindergarten programs.

As previously noted, there has been increasing interest since the 1990s in both South Korea and Malaysia with respect to the reform, development, and advancement of the educational systems. The growing interest in pre-primary education was the result of a combination of factors that were active during that decade, most notably the rising tide of economic globalization and market liberalization. These events were quickly followed by the adoption of reform programs and educational advancements focused on creating productive, conscientious and creative individuals. This goal can be achieved by developing policies and strategies that reconsider and reevaluate the many educational practices and activities of the educational process and that place an emphasis on human development.

\section{The Relationship between Pre-Primary Education in South Korea and Malaysia and the Experience of Saudi Arabia}

The pre-primary education level must be continuously reviewed in terms of the teaching, preparation, curriculum, and equipment provided in the learning environment as should all related aspects of this important stage in a child's life. Any development during this phase must be translated to new responsibilities, specific skills and an effective system to manage and assess growth. This, in turn, will translate the mechanisms and the development agenda into operational plans, practical reality and clear responsibilities that take into account the advancements in scientific research directed towards education, thus reinforcing the importance of this stage of education. There is a deep understanding and consensus among decision makers in Saudi Arabia regarding the importance of kindergarten and its effect on the child's psychological, educational and social development, as is the case in the countries studied herein. Through the project of King Abdullah bin Abdul-Aziz, the government of Saudi Arabia allocates a large budget for the development of all stages of public education, including preprimary education, as is the case with the governments of Malaysia and South Korea, both of which allocate huge budgets to ensure that their children are enrolled in kindergarten programs.

The reform and development of the educational systems in South Korea and Malaysia have experienced a surge of interest since the 1990s. Similarly, there has been a noted increase in interest in Saudi Arabia. In response to this growing interest, Saudi Arabia adopted a systematic, integrated program that consists of educational projects. This was ultimately the result of a specialized company created specifically to develop programs 
and projects that will advance education in Saudi Arabia. The company is called Tatweer.

The plan of the Ministry of Education in Saudi Arabia is to invest in early childhood care as such an investment is an investment in a child's life, and as such, it has great returns for the community in all stages of life. The importance of pre-primary education lies in its being the foundational stage for all other stages, wherein the ability to learn, to control movement, to control thoughts, to express emotions and to adjust socially are the basis for future education. In spite of the efforts of public education, it has been determined that by the age of eight, it is too late to attend to the educational needs of children as most of the cerebral basic links, linguistic preparations, and cognitive and physical abilities have already matured. Hence, early childhood care and nurturing play a crucial role in preparing the child for learning. The kingdom's decree No. (7/b/5388) on 03/03/1423 AH emphasized this importance by making kindergarten an independent program in its buildings and separating it from the other educational stages, by developing a time line for the development plans to establish kindergartens throughout the kingdom, by involving the private sector in this goal, and by developing dynamic educational curricula for kindergarten to achieve the objectives of this stage (Ministry of Education, Saudi Arabia, 2013).

Pre-primary teaching received great attention and support from the Ministry of Education in the Eighth Development Plan where the kingdom's decree No. (7/b/5388) dated 03/03/1423 AH (2002) directed the Ministry of Education to develop a plan and timetable that aligns with the development plan for the kingdom and that aims to create the gradual expansion of kindergartens throughout the kingdom in collaboration with the private sector and with the agreement to build an effective educational curriculum for kindergartens. As a result of this interest, the number of children enrolled in kindergartens has increased from approximately 96,000 in 2004 to $100,030,000$ in 2008. In addition, the eighth development plan saw the release of Cabinet Resolution No. (60) on 28/02/1430 (2009). As evidenced in the minutes of the Ministerial Committee for Administrative Organizations, it was proposed to study the increase in women's employment opportunities in suitable areas within government agencies. Such a proposal emphasizes the need to make kindergarten an integral part of the education track and eliminate restrictions on employment of women (Ministry of Economy and Planning, 2013). Table 5 shows the evolution of kindergarten under the eighth development plan of Saudi Arabia.

There are many similarities noted between Saudi Arabia and the two countries compared herein, which call for Saudi Arabia to adopt curriculum reforms and development all stages of education, including the pre-primary stage. In addition to economic prosperity, economic globalization and market liberalization, all three countries-South Korea, Malaysia and Saudi Arabia-have adopted economic and educational reform programs to keep up with the current advancements and innovations in preparation for creating active, productive, skilled individuals who can contribute to the labor force.

\section{Educational and Social Aspects of the Study}

Despite these similarities, there are some differences in the social factors between Saudi Arabia and the two countries studied herein. The Saudi society, for example, is much more private than Malaysian and South Korean societies. Furthermore, the Saudi community is more attached to its culture, traditions and heritage, and accordingly, is more cautious when dealing with changes and new developments, especially when they do not converge with the traditional culture and customs. Therefore, the development of curricula for the pre-primary education stage must customized so it aligns with the culture and traditions of the Saudi society. Privacy, for instance, must be valued at the kindergarten stage as this is the first educational and social institution with which the child comes in contact come into contact. However, it is also essential that Saudi kindergarten intersects in its curricula and functions with the curricula and functions of the Malaysian and South Korean kindergartens in

Table 5. The evolution of kindergarten under the eighth development plan of Saudi Arabia ( ${ }^{*}$ ).

\begin{tabular}{cccc}
\hline & 2004 & 2008 & Average Annual Percentage Growth \\
\hline Kindergarten & 1396 & 1472 & 3.1 \\
Classes & 5514 & 6568 & 5.4 \\
No. of Children Enrolled & 96,073 & 103,125 & 3 \\
No. of Teachers & 10,049 & 10,184 & 3 \\
\hline
\end{tabular}

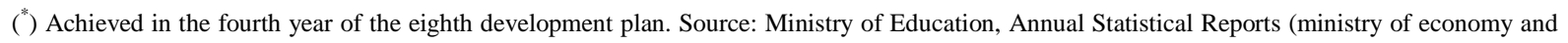
planning report of the ninth development plan, p. 362). 
its quest to achieve the following objectives.

1) Develop the child's personality, teach the child new skills and provide the child with learning experiences.

2) Build healthy habits with respect to the child's educational and properly prepare the child for primary school enrollment.

These objectives can only be achieved by offering a modern curriculum that considers the child to be the center of all its activities and that adopts practical experiences, elements of discovery, awareness and self-contained intellectual creativity and skills as part of its strategy. This is the case in the curricula of both the South Korean and the Malaysian kindergartens, which employ excellent educational cadres to teach this educational stage and which adopt a clear educational philosophy and clear behavioral, psychological and procedural objectives that are based on science.

The significance of this educational stage is the result of a deep belief in its importance and in the educational goal that the way to a child for the next stage in his development is to provide him with sound cultural and social experiences that are commensurate with the child's abilities and aptitudes (Al-Aqeel, 1426: p. 53). This goal can be achieved by providing the child rich educational activities and social experiences such as sports; visits to cultural activities; acting opportunities; lessons in morals, ethics, art education, crafts, and music and basic skills in reading, writing and arithmetic (Al-Aqeel, 1426: p. 55).

Therefore, it is important to provide a rich learning environment that is conducive to supporting the children's growth and development. Thus, it is necessary to improve the training of teachers, to provide the right tools and space sufficient to activate the programs and curricula and to investigate the factors that will enhance the educational environment of preschool institutions. The dynamic educational environment is a complex combination of both social and physical environments, where both are intertwined and complement one another and both are of equal importance. The elements of the social environment include the management of the classroom and the ability to control and modify the behavior of children by using, for example, techniques and strategies for direct guidance (Hare, 2006).

All activities and programs designed for the child at this stage must incorporate an integrated, flexible educational system that fits the capabilities and potentialities of the child and meets his needs and characteristics. Furthermore, the program must be administered by a teacher who is academically and professionally qualified to achieve the objectives of this important stage of education.

\section{A Proposal for the Development the Pre-Primary Education in the Kingdom of Saudi Arabia}

- When projecting on future changes anticipated in the Saudi society, there is an evident increase in the demand for kindergarten services. The Ministry of Education has received numerous requests to establish kindergarten institutions throughout the kingdom. Thus, the number of kindergartens continues to grow due to the rapid increase in birthrates in Saudi Arabia, the awareness of Saudi families regarding the importance of kindergarten in the child's life, and the increase in the number of women working outside their homes as a result in the shift from extended to nuclear families in Saudi society. This rapid increase in kindergarten institutions must be accompanied by the radical development in the administrative system as it will face challenges organizing and supervising these kindergarten centers. Such challenges and difficulties have been evidenced through the negative effects of kindergarten (Al-Otaibi \& Suwailem, 2002: p. 57).

- The need for kindergarten in the Saudi society is based the demographic changes that have occurred during the last three decades, the structural transformation of the family from a large extended family to a small nuclear family, the cultural shift of the social classes, and the increased awareness of the importance of a pre-primary educational program, due to its positive role in all respects of children's development and preparation for primary education. The increased need has resulted in the expansion of public and private kindergartens in all parts of the Kingdom. The number of females in public kindergartens is presented in Table 6.

- Kindergartens are educational and social institutions that seek to educate children and qualify them for primary school enrollment, thus making the sudden shift from home to school less traumatic and problematic. The kindergarten program allows children the freedom to engage in activities and discover their abilities, inclinations and capabilities. Kindergartens help children gain new skills and experiences. The children in this stage are between three and six years. At this age, children need constant encouragement from their teachers to develop an appreciation for teamwork; to instill a spirit of cooperation, positive active participation, 
Table 6. Number of females in public kindergartens in Saudi Arabia.

\begin{tabular}{cccccc}
\hline Location & Type & Academic Year & No. of Kindergartens & No. of Classes & $\begin{array}{c}\text { No. of } \\
\text { Female Students }\end{array}$ \\
\hline Jeddah & Public & $2003 / 2004$ & 23 & 129 & 2140 \\
Jeddah & Private & $2003 / 2004$ & 155 & 610 & 9587 \\
Rest of Saudi Arabia & & $2005 / 2006$ & 1159 & 5316 & 94,786 \\
\hline
\end{tabular}

self-reliance, and self-confidence; to acquire social and language skills; and to form sound trends, habits, and attitudes regarding the educational process.

- Kindergarten must be considered a purposeful educational stage that is no less important than other educational stages. As such, it is a distinct educational stage with its own educational philosophy, behavioral objectives and teaching and learning psychology.

- The objectives of kindergarten must be based on self-respect, self-confidence, stimulating creativity and independent thinking. It must encourage the child to adapt to change without fear, promote physical well-being, and positive health habits. It must helping children learn to live, work and play with others and promote an appreciation for music, art and nature.

- The need to benefit from contemporary educational research, which states, "The educational role of the kindergarten is the development of the child's personality traits; the child's physical, mental and motor aspects; and the child's linguistic, emotional and social aspects to help the child express himself. It also helps the child to integrate with peers, develop respect for the rights and privacy of others and for public property, develop the child's ability to solve problems, prepare the child for formal education and impart the concepts and skills of religious education, Arabic language, mathematics, arts, music, health education and social services. In addition, it prepares the child for the natural transition from family to school after age six and it develops the child's self-confidence as an individual who has his own abilities and features” (Badran, 2000).

- "The inspector of global modern trends of servicing childhood and caring for kindergarten institutions sees disappointing significant differences between the reality of childhood and its modest educational institutions in Saudi Arabia and the recent trends in countries of the world, especially the countries that have made from the beginning of the third millennium a new formulation of kindergarten goals. For example, South Korea and Malaysia have provided premium quality education and care for preschool children as they recognize the importance of kindergarten on a child's mental, educational and social life. The governments of these countries allocated large budgets to ensure free enrollment of children in government kindergarten programs without financial burdens on their families, and provide kindergarten institutions with all needed requirements to ensure that the objectives of the kindergarten are met” (Al-Otaibi \& Suwailem, 2002). This is a clear indicator of educational policy, and it calls for Saudi Arabia to reconsider the terms and planning objectives for its kindergarten program.

- Herein, we refer to the recent efforts made by Saudi Arabia to develop this phase, which is a move that intersects the characteristics and features of the countries compared in this study. This is achieved primarily through the adoption of curricula that are aligned with the standards of global education and the acquisition of capable human resources to effectively implement the curricula in schools and educational departments through the training of teachers, school leaders and supervisors. This contributes to raising the level of achievement of children at this important educational stage and prepares them for later educational stages. Such attention directed to the proper design of curricula was common in both South Korea and Malaysia.

- Tatweer provides educational services and builds strategic partnerships with institutions and educational companies that have developed integrated curriculum approaches that are supported by appropriate educational means and tools and based on global educational standards for kindergarten. The company also supports the application process, provides for the transfer of knowledge through the training of teachers and supervisors, and ensures the quality of the application of materials. Hence, the services provided by Tatweer will lead to the achievement of the objectives of the strategy for the development of public education in the kingdom of King Abdullah bin Abdul-Aziz, who posits that the development of public education depends not only on the educational system but on the participation of all sectors, members and institutions of society. Under King Abdullah bin Abdul-Aziz's direction, Tatweer is to conduct training workshops for kindergarten supervisors titled "Acers scale to evaluate the learning environment", a program devoted to the evaluation of 
the kindergarten environment. This training was part of a series of training programs offered by the project to develop kindergarten curricula. The kindergarten curricula development project sought to adopt curricula that were aligned with global educational standards and build the required capacity for effective implementation in schools and educational departments through the training of teachers, school leaders and supervisors, which would raise the level of achievement of children in this educational stage and prepare them for the subsequent stages of their education (King Abdullah Project for the Development of Online Public Education, 2013).

Consequently, the author suggests there be a focus on the following concepts.

- The administrative and supervisory responsibilities of kindergarten institutions are filled with challenges and educational needs that influence educational policy and result in the need to revisit the kindergarten position on the educational ladder. Thus, the kindergarten stage should be considered an economic investment, as well as an educational and social investment, as it is the foundation for future generations.

- The bodies supervising the process of education should have a conscious awareness of the nature of the innovations and the development of educational systems, as they are social systems that interact with the environment and go through continual changes.

\section{Recommendations}

In light of the outcome of the current study and the aforementioned requirements, the researcher proposes the following recommendations.

-To increase the degree of compatibility between the size of the administrative education system and the requirements and conditions of employment in the field, and accordingly, move towards a decentralized management style that is void of bureaucracy. This will strengthen the institutional and collective work by establishing the principle of accountability to ensure outstanding achievement and by promoting a comprehensive quality and accountability educational philosophy in training courses and programs.

-To increase the complementary relationship with the private sector and encourage the private sector's role in the educational process by making it easy to invest in the development of excellent programs and pilot projects at the kindergarten levels.

-To ensure that teachers are aware of the objectives of the kindergarten program by holding intensive training courses in the areas of teaching methodology and with respect to the appropriate treatment and behavior of children. Such trainings should focus on enriching teacher creativity by providing exciting examples and exercises that teachers can easily implement in the classroom and by providing them with the tools and technical equipment necessary for successful teaching.

-To re-evaluate the kindergarten teacher preparation programs for improvements and redevelopment and thus provide empowered, innovative strategies and modern educational methodologies for implementation in the teaching and learning process.

-To provide enriched quality programs that integrate technology and curriculum geared to kindergarten children.

-To provide public and private kindergarten institutions with specialized teachers and provide these teachers with ongoing training.

-To establish school buildings for nurseries and kindergartens, in the Kingdom of Saudi Arabia in accordance with the requirements and specifications for kindergarten programs to meet the needs of education. This is contrary to what currently exists in Saudi's contemporary educational systems. It is necessary to create schools that are dedicated to children at the kindergarten age that have such features as parks, playgrounds, toys, equipment, furniture, technology, as observed in institutions and kindergartens in Malaysia, South Korea, and other contemporary educational systems.

-There are many factors and cultural forces behind these shortcomings, and it is possible that the economic boom led to the expansion of kindergartens without adequate preparation. Thus, there are issues regarding building appropriateness and the hiring of teachers and school principals who lack the ability and efficiency to successfully manage these institutions.

-To strengthen the relationship between the Ministry of Education in the Kingdom of Saudi Arabia and the local universities to benefit from research and scientific studies related to early childhood and kindergarten curriculum design and teaching methodology. 
-To develop a preschool education curriculum that promotes self-respect, self-confidence, creative thinking and constructive habits and behaviors.

-To model and adopt teaching strategies deemed appropriate for children at this stage, including learning through play, cooperative learning, and role-playing strategies.

-To benefit from the creative approach used in Malaysia and South Korea that is based on an educational philosophy that clearly meets the individual needs of each child.

-To provide effective and active kindergarten programs that keep pace with the growth of the child and that incorporate early childhood education practices that are similar to those found in Malaysia and South Korea.

\section{Conclusion}

Based on the experiences of South Korea and Malaysia, this study concludes with the following proposals:

- The formation of a committee to study distinguished successful international pre-primary educational programs and formulate a strategy for the development of this educational stage in Saudi Arabia. The committee should also assess the suitability of the curriculum offered by Tatweer, a company that provides educational services, for kindergarten programs and measure the feedback of the results on students at this stage.

- The need for the Ministry of Education in coordination with the media in Saudi Arabia to conduct comprehensive awareness programs regarding the importance of these institutions and provide education programs for parents to learn the fundamentals of raising a child of this early age.

- The need to conduct periodic evaluations of private kindergartens in Saudi Arabia every two or three years to assess their educational processes, their progress, and their degree of research.

- The need to prepare a detailed list of curriculum standards appropriate for students at this stage.

- The need to build a curriculum that aligns with the standards of the global curriculum while taking into account the characteristics of Saudi society.

- The need to build a curriculum that is based on sound educational philosophy and clear scientific grounds that takes into account the child's needs and abilities.

Finally, with these proposals, the establishment of kindergartens in Saudi Arabia will definitely enhance the development of children in all respects_-psychologically, academically, socially, etc.—and will thus contribute to building the future generation.

\section{References}

Abdul-Aal, A. M. A. (2006). Department of Education in both China and South Korea, Malaysia and the Possibility of Access to Them in Egypt. Published Studies, Sohag: The College of Education Publications Sohag University.

Abdul-Halim, T. H. (2002). Development of a Training System for Kindergarten Teachers in Egypt in Light of the Choices of Some Developed Countries: A Prospective Study. Unpublished Ph.D. Thesis, Helwan: Faculty of Education, Helwan University.

Abu Bakr, M. M., \& Ali, N. H. (2013). Requirements for the Development of Kindergarten in Egypt in Light of Experiences of USA and France: A Comparative Study. (Accepted for Publication). Journal of the Faculty of Education, 2, 24-44.

Al-Aqeel, A. A. (1426). Education Policy in Saudi Arabia. Riyadh: Al-Rashid Bookstore.

Al-Fayez, H. S. (1418). Integration of Children with Special Needs in Ordinary Kindergarten Institutions. Riyadh: Al-Farazdaq Press.

Al-Hamundy, J. (2011). Education in Korea: The Insistence on Continual Progress. Journal of Knowledge, 4, 36-54.

Al-Mahyawi, Q. (2007). University Management in Light of Overall Quality Standards. Journal of the Federation of Arab Universities.

Al-Otaibi, M. M., \& Suwailem, B. H. (2002). The Objectives of Early Education (Kindergarten) in Saudi Arabia: An Analytical Study. A Study Submitted to the Center for Educational Research, Riyadh: Faculty of Education, King Saud University.

Al-Rashed, M. A. (1419). The Implications of the Concept of Role Models as Perceived by Kindergarten Teachers and the Degree of Practicing Them. Master Thesis (Unpublished), Riyadh: College of Education, King Saud University.

Al-Rashidi, B. S. (2000). Educational Research Methods: A Simplified Applied Vision. Kuwait: Dar Alketab Alhadith (Modern Books Publisher).

Al-Shayji, O. A. (2013). A Comparative Study of the Management and Financing of Pre-School Education in Saudi Arabia and Kuwait. Master Thesis (Unpublished), Riyadh: Faculty of Education, King Saud University. 
Al-Warthan, A. A. (2011). Malaysian Education System, Quality and Proficiency. Journal of Knowledge, 179, 88-119.

Al-Zaki, A. A. (2010). Education in Malaysia: Wide Choices for Students at the Secondary Level. Journal of Knowledge, 179, 21-45.

Badran, S. (2000). Recent Trends in Raising Pre-School Children. Cairo: Egyptian-Lebanese Publishing House.

Bashir, M. S. (2003). Investing Humans in Malaysia, a Study Published in "Islam Online”. http://www.islamonline.net/arabic

Braithwaite, J. (1983). Explorations in Early Childhood Education. Hawthorn, Victoria: Australian Council for Educational Research.

Fathi, S. M. et al. (1996). Comparative Education: Methodology and Education Basics in Europe, East Asia, Arabian Gulf and Egypt. Cairo: House of Wisdom Publishing and Media.

Global Arabic Encyclopedia (1416). Malaysia. Part (22), Business Encyclopedia Establishment for Publication and Distribution. Riyadh.

Hare, J. (2006). Working with Young Children (Arabic Version). Jordon: Al-Darr Al-Ahliyah Publishing House.

Hussein, S. (2005). Accreditation and Quality Assurance in Education. Cairo: Darr Al-Nahdah Alarabis Publishing and Distribution.

Khalil, N. S. (2002). Department of Education in the Republic of South Korea and the Possibility of Benefiting from It in the Development of the Education Management in Egypt. Journal of the Faculty of Education, 18, 117-145.

King Abdullah bin Abdul-Aziz Project for the Development of Online Public Education (2013). www.tatweer.edu.sa

Korean Overseas Information's Service (2004). A Handbook of Korea (8th ed.). Korea: Samhwa Printing Company, Ltd.

Le Normand, M. T. (1992). Early Childhood Education in France. International Handbook of Early Childhood Education (pp. 205-216). New York: Garland.

Malaysian Consulate (2003). The National Educational System, Guide to Malaysian Studies (English Version). Jeddah.

Malaysian Consulate (2006). Education in Malaysia. Jeddah: Educational Media Council in Malaysia. (In English)

McMahan, I. D. (1992). Public Preschool from the Age of Two: The Ecole Maternelle in France. Young Children, 47, 22-28.

Meisels, S. J. (1999). Assessing Readiness. In R. C. Pianta, \& M. Cox (Eds.), The Transition to K.G.: Research, Policy, Training, and Practice (pp. 61-89). Baltimore, MD: Paul Brookes Publishers.

Ministry of Economy and Planning, Kingdom of Saudi Arabia (2013). Report of the Ninth Development Plan, Chapter 22. Riyadh.

Ministry of Education (2004). “Development of Education”. National Report Malaysia, the Development of Education.

Ministry of Education, Saudi Arabia (2013). www.moe.gov.sa (Education Policy)

Mohammed, A. M. (2006). A Comparative Study of Training Programs for Kindergarten Teachers in Service in Egypt and the United Kingdom in Light of Global Goals for Kindergarten Education. Unpublished Master Thesis, Cairo: University of Ain Shams.

Mohammed, M. A. (2002). A Productive School. Journal of Educational Sciences, 2, 177-201.

Ochiltree, G., \& Edgar, D. (1990). The Effects of Non-Maternal Care in the First Twelve Months of Life on Children in the First Year of School: Preliminary Findings from a Two Stage Study (The Australian Early Childhood Study). Melbourne: Australian Institute of Family Studies.

Osborn, A. F., \& Milbank, J. E. (1987). The Effects of Early Education: A Report from the Child Health and Education Study. Oxford: Clarendon Press.

Rhee, U., \& Lee, K. (1990). The Effectiveness of Four Early Childhood Program Models: Follow-Up at Middle School. Journal of Educational Research, 28, 147-162.

Salim, M. E. (1995). Asian Studies and Its Evolution. Journal of International Politics, 4, 11-23.

Sasila, R. (2008). A Proposed Strategy for Developing a System for Kindergarten Teacher Training in Light of Contemporary Educational Trends. Damascus: Faculty of Education, University of Damascus.

Schweinhart, L. J., Barnes, H. V., \& Weikart, D. P. (1993). Significant Benefits: The High/Scope Perry Preschool Study through Age 27. Monographs of the High/Scope Educational Research Foundation, No. 10. Ypsilanti, MI: High/Scope Press.

Sim, K. P., \& Kam, H. W. (1992). Growing up in Singapore: The Preschool Years. Singapore City: Longman Singapore.

Tietze, W. (1987). A Structural Model for the Evaluation of Preschool Effects. Early Childhood Research Quarterly, 2, 133-153. http://dx.doi.org/10.1016/0885-2006(87)90040-8 
Scientific Research Publishing (SCIRP) is one of the largest Open Access journal publishers. It is currently publishing more than 200 open access, online, peer-reviewed journals covering a wide range of academic disciplines. SCIRP serves the worldwide academic communities and contributes to the progress and application of science with its publication.

Other selected journals from SCIRP are listed as below. Submit your manuscript to us via either submit@scirp.org or Online Submission Portal.
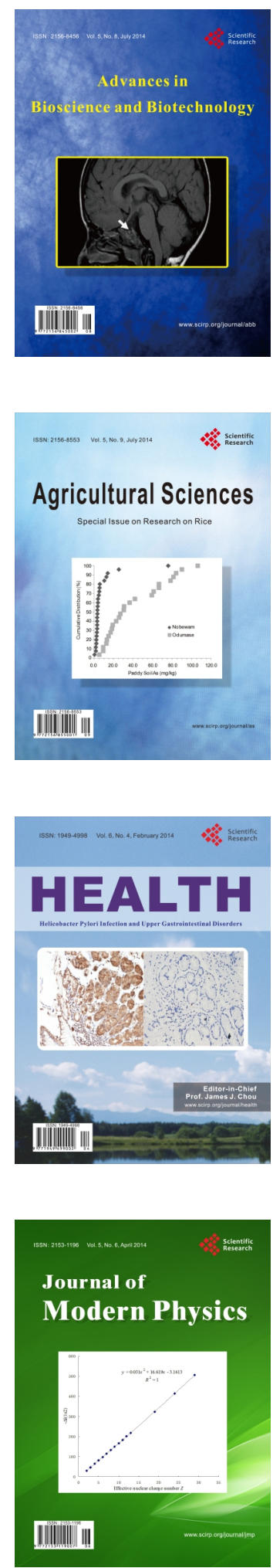
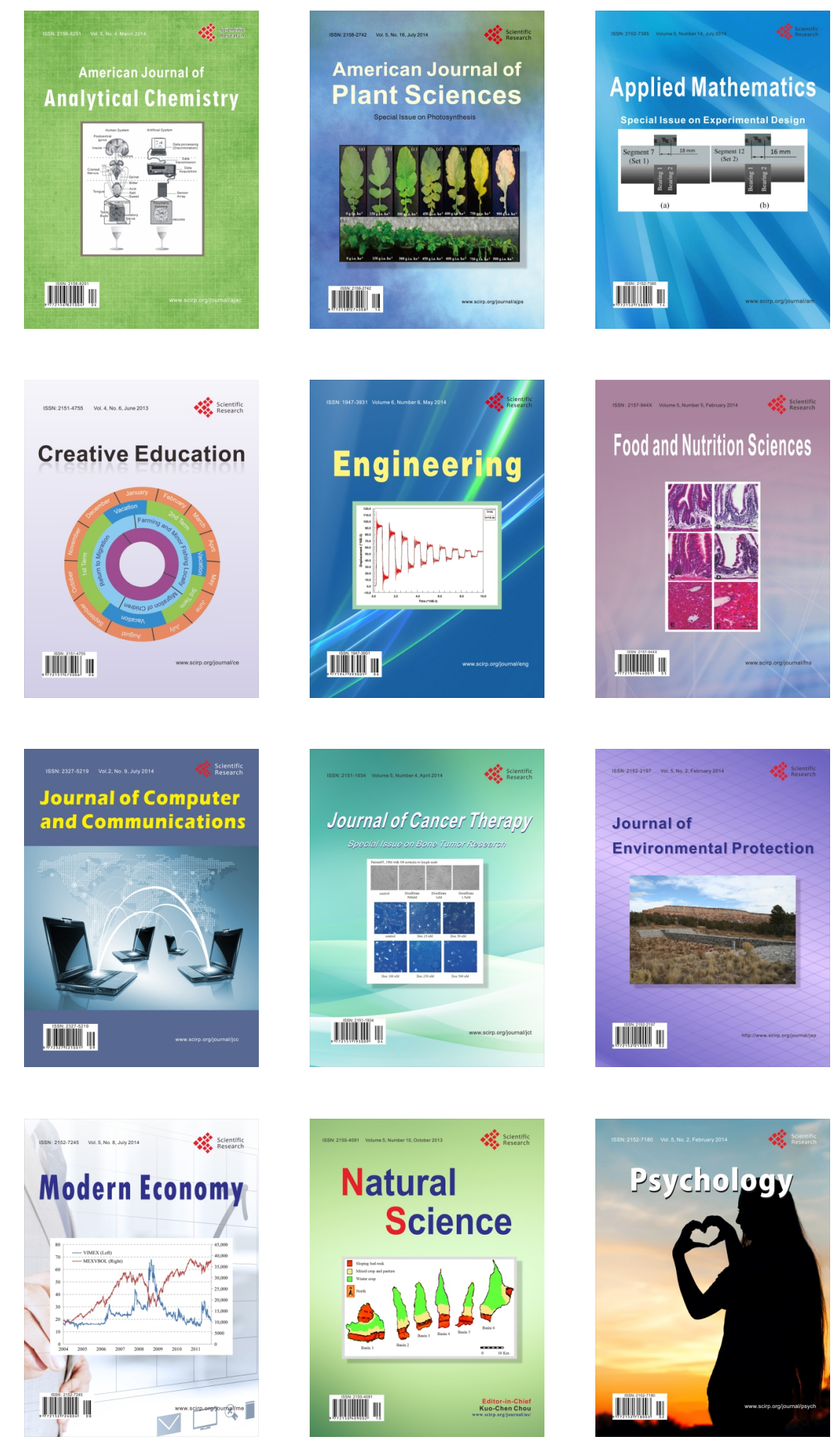